\title{
Short- and Long-term Outcomes of Surgical Treatment for Remnant Gastric Cancer After Distal Gastrectomy
}

\author{
YU NAKAJI ${ }^{1}$, HIROSHI SAEKI ${ }^{1}$, KENSUKE KUDOU $^{1}$, RYOTA NAKANISHI ${ }^{1}$, MASAHIKO SUGIYAMA $^{1}$, \\ YUICHIRO NAKASHIMA ${ }^{1}$, KOJI ANDO ${ }^{1}$, YOSHINAO ODA ${ }^{2}$, EIJI OKI ${ }^{1}$ and YOSHIHIKO MAEHARA ${ }^{1}$ \\ ${ }^{1}$ Department of Surgery and Science, Graduate School of Medical Sciences, \\ Kyushu University, Fukuoka, Japan; \\ ${ }^{2}$ Department of Anatomic Pathology, Pathological Sciences, \\ Graduate School of Medical Sciences, Kyushu University, Fukuoka, Japan
}

\begin{abstract}
Background/Aim: Remnant gastric cancer (RGC) after distal gastrectomy occurs in 1-2\% of patients, while the biological features of RGC are unknown. Patients and Methods: A total of 22 consecutive patients with RGC who underwent total gastrectomy were analyzed. Their disease history included either gastric cancer $(n=16)$ or peptic ulcer $(n=6)$. Overall, 18 underwent open total gastrectomy (OTG) and 4 underwent laparoscopic total gastrectomy (LTG). Results: The mean number of lymph nodes dissected and metastatic lymph nodes was larger in the Ulcer group than in the Carcinoma group $(p<0.005)$. The mean operation time was longer in the LTG than OTG $(p<0.005)$. The median blood loss tended to be smaller in the LTG $(p=0.090)$. Fiveyear overall and recurrence-free survival rates were $94 \%$ and $81 \%$, respectively. Conclusion: The status of lymph node metastasis after surgery for RGC should be cautiously considered in the context of disease history. Both LTG and OTG can be treatment options for RGC.
\end{abstract}

Incidence of remnant gastric cancer (RGC) is increasing due to previous improvements in the detection of gastric cancer and improved medical care (1). RGC after distal gastrectomy has been reported to occur in $2-3 \%$ of patients who have undergone gastrectomy for carcinoma or benign disease and was reported to account for $1-2 \%$ of all gastric cancers in Japan (2). RGC is caused by the continuous bathing of the gastric remnant with bile acids or duodenal

Correspondence to: Hiroshi Saeki, MD, Ph.D., FACS, Department of Surgery and Science, Graduate School of Medical Sciences, Kyushu University, 3-1-1 Maidashi, Higashi-ku, Fukuoka 812-8582, Japan. Tel: +81 926425466, Fax: +81 926425482, e-mail: h-saeki@surg2.med.kyushu-u.ac.jp

Key Words: Remnant gastrectomy, lymph node dissection, laparoscopic operation, prognosis. juice, resulting in repeated mucosal inflammation and regeneration (3). RGC is commonly detected at an advanced stage, resulting in low rates of curative resection (38-40\%), and prognosis is reported to be worse than that of patients with primary cancers in the proximal third of the stomach at the same stage (1). However, the clinical features of and surgical results for RGC have not been fully elucidated.

Laparoscopic surgery for gastric cancer is widely used. Surgical treatment for RGC is more difficult than for primary gastric cancer due to adhesions to adjacent organs, displacement of anatomical structures, and changes in lymphatic flow. Laparoscopic gastrectomy for remnant gastric cancer has also been reported sporadically in association with the increased use of minimally-invasive techniques. However, because of the rarity of remnant gastric cancer, the number of cases reported per study has been small. Here, we report the short-term results of laparoscopic surgery for RGC in our institute (4).

The aim of this study was to clarify the clinicopathological features and results of surgical treatment of RGC following distal gastrectomy with regard to previous gastric disease and surgical approach used.

\section{Patients and Methods}

Patients. RGC was defined as gastric cancer in the remnant stomach arising more than five years after distal gastrectomy for benign disease or gastric cancer (3). Between 2004 and 2014, 22 patients underwent surgery for remnant gastric cancer after distal gastrectomy in our institute. A total of 18 men and 4 women enrolled in the study, and the mean age was 73.9 years. Previous disease was gastric cancer in 16 patients $(72.7 \%)$ and peptic ulcer in 6 patients $(27.3 \%)$. Eighteen patients underwent open total gastrectomy (OTG) and 4 patients underwent laparoscopic total gastrectomy (LTG). The indication of a laparoscopic approach toward RGC was the same as that toward primary gastric cancer from 2013 (4). 
Methods. Clinical stage was classified according to the TNM classification (5). Postoperative complications occurring within 30 days after operation were classified according to the Clavien-Dindo classification (6). Clinicopathological features and surgical results were analyzed in terms of previous disease (Ulcer vs. Carcinoma) and surgical procedures (OTG vs. LTG).

Statistics. JMP (SAS, USA) was used for statistical analyses. The chisquare test and Student's $t$-test were applied for assessment of various factors. The Kaplan-Meier method was used to present the survival data. A value of $p<0.05$ was assumed to indicate statistical significance.

\section{Results}

Comparisons between the Ulcer group and the Carcinoma group. The clinicopathological features of RGC according to previous disease (Ulcer group vs. Carcinoma group) are shown in Table I. There were no significant differences in various factors between the two groups.

Surgical results and pathological findings according to the two groups are shown in Table II. The mean number of lymph node dissection and lymph node metastasis were 12.4 (25 in the Ulcer group vs. 8 in the Carcinoma group; $p<0.005$ ) and 0.95 ( 3 in the Ulcer group vs. 0.3 in the Carcinoma group; $p<0.05)$, respectively. The mean tumor diameter was $3.6 \mathrm{~cm}$ (5.6 $\mathrm{cm}$ in the Ulcer group, $2.9 \mathrm{~cm}$ in the Carcinoma group; $p<0.05)$. The mean interval between the first and the second operation was 19.1 years (35 years in the Ulcer group $v s .12$ years in the Carcinoma group; $p<0.0001)$. The mean operation time was $347 \mathrm{~min}$ ( $260 \mathrm{~min}$ in the Ulcer group, vs. $380 \mathrm{~min}$ in the Carcinoma group; $p=0.079$ ).

Comparisons between the OTG group and the LTG group. Clinicopathological features of RGC according to surgical procedure are shown in Table III. There were no significant differences in various factors between the two groups.

Surgical results and pathological findings according to surgical procedure are shown in Table IV. The mean number of lymph node dissections was 11 in the OTG group vs. 15 in the LTG group; there was no significant difference. The mean operation time was longer in the LTG group than in the OTG group (455 min vs. $293 \mathrm{~min} ; p 0.005$ ). The mean intraoperative blood loss tended to be larger in the OTG group than in the LTG group (625 $\mathrm{g} v s .158 \mathrm{~g} ; p=0.09$ ).

There were two cases that experienced postoperative complications in the LTG group (pneumonia: 1, bleeding: 1) and five cases in the OTG group (minor leakage: 1, bile leakage: 1 , bleeding: 1 , surgical site infection: 2 ) There were no cases with in-hospital death in either group.

The mean time to postoperative resumption of food intake was not significantly different between the two groups (OTG 8 days $v s$. LTG 6 days; $p=0.168$ ). The length of postoperative hospital stay was similar between the two groups (OTG 16 days $v s$. LTG 15 days; $p=0.655$ ).
Table I. Clinicopathological characteristics of remnant gastric cancer according to previous disease (Ulcer group vs. Carcinoma group).

\begin{tabular}{|c|c|c|c|c|}
\hline \multirow[b]{2}{*}{ Factor } & \multicolumn{2}{|c|}{ Previous disease } & \multirow[b]{2}{*}{ Total } & \multirow[b]{2}{*}{$p$-Value } \\
\hline & $\begin{array}{l}\text { Ulcer } \\
(\mathrm{n}=6)\end{array}$ & $\begin{array}{l}\text { Carcinoma } \\
\quad(\mathrm{n}=16)\end{array}$ & & \\
\hline \multicolumn{5}{|l|}{ Gender } \\
\hline Male & $6(100)$ & $12(75.0)$ & $18(81.8)$ & 0.176 \\
\hline Female & $0(0)$ & $4(25.0)$ & 4 (18.2) & \\
\hline \multicolumn{5}{|l|}{ Age (mean) } \\
\hline$<65$ & $1(16.7)$ & $2(12.5)$ & $3(13.6)$ & 0.799 \\
\hline$>65$ & $5(83.3)$ & $14(87.5)$ & $19(86.4)$ & \\
\hline \multicolumn{5}{|l|}{ Depth of tumor } \\
\hline $\mathrm{T} 1 / 2$ & $3(50)$ & $10(62.5)$ & $13(59.0)$ & 0.595 \\
\hline $\mathrm{T} 3 / 4$ & $3(50)$ & $6(37.5)$ & $9(41.0)$ & \\
\hline \multicolumn{5}{|c|}{ Lymph node metastasis } \\
\hline No & $3(50)$ & $13(81.3)$ & $16(72.7)$ & 0.143 \\
\hline $\mathrm{N} 1$ & $3(50)$ & $3(19.7)$ & $6(27.3)$ & \\
\hline \multicolumn{5}{|l|}{$\begin{array}{l}\text { Differentiation of } \\
\text { adenocarcinoma }\end{array}$} \\
\hline Well/moderate & $5(83.3)$ & $8(50)$ & $13(59.0)$ & 0.157 \\
\hline Poorly & $1(16.7)$ & $8(50)$ & $9(41.0)$ & \\
\hline \multicolumn{5}{|c|}{ Lymphatic invasion } \\
\hline Ly $(-)$ & $3(50)$ & $7(43.8)$ & $10(45.4)$ & 0.793 \\
\hline Ly $(+)$ & $3(50)$ & $9(56.2)$ & $12(54.6)$ & \\
\hline \multicolumn{5}{|l|}{ Vascular invasion } \\
\hline $\mathrm{V}(-)$ & $5(83.3)$ & $11(68.8)$ & $16(72.7)$ & 0.494 \\
\hline $\mathrm{V}(+)$ & $1(16.7)$ & $5(31.2)$ & $6(27.3)$ & \\
\hline \multicolumn{5}{|l|}{ Pathological stage } \\
\hline I & $3(50)$ & $9(56.3)$ & $12(54.5)$ & 0.180 \\
\hline II & $1(16.7)$ & $7(43.7)$ & $8(36.3)$ & \\
\hline III & $2(33.4)$ & $0(0)$ & $2(9.2)$ & \\
\hline
\end{tabular}

Overall survival and relapse free survival. Five cases received adjuvant chemotherapy after operation for RGC (pStage II: 3 cases, pStage III: 2 cases). There were two postoperative recurrences. One case had para-aortic lymph node recurrence and died ten months after surgical operation (Carcinoma group, pT4a N0 M0 pStage IIB, ly3, v2). Another case had intraabdominal lymph node recurrence and died eleven months after surgical operation (Carcinoma group, pT3 N1 M0 pStage IIB, ly3, v0). The five-year overall survival and recurrence-free survival rate was $94 \%$ and $81 \%$, respectively (range of observation period $=11-194$ months) (Figure 1).

\section{Discussion}

In previous studies, it has been suggested that RGC is commonly detected at an advanced stage, thereby resulting in low rates of curative resection (38-40\%) and a poor prognosis (1). The exact reasons for this poorer survival are not clear, but the disruption of lymphatic channels during the 
Table II. Surgical results and pathological findings according to previous disease (Ulcer group vs. Carcinoma group).

\begin{tabular}{|c|c|c|c|}
\hline & \multicolumn{2}{|c|}{ Previous disease } & \multirow[b]{2}{*}{$p$-Value } \\
\hline & Ulcer group $(n=6)$ & Carcinoma group $(n=16)$ & \\
\hline Number of lymph node dissections (mean) & 25 & 8 & $<0.005$ \\
\hline Number of lymph node metastasis (mean) & 3 & 0.3 & $<0.05$ \\
\hline Tumor size $(\mathrm{cm}$, mean $)$ & 5.6 & 2.9 & $<0.05$ \\
\hline Interval between 1st and 2nd operations (years, mean) & 35 & 12 & $<0.0001$ \\
\hline Operation time (min, mean) & 260 & 380 & 0.079 \\
\hline Blood loss (ml, mean) & 422 & 599 & 0.460 \\
\hline Complication & 0 & 6 & 0.350 \\
\hline Minor leakage & 0 & 1 & \\
\hline Bile leakage & 0 & 1 & \\
\hline Bleeding & 0 & 1 & \\
\hline Surgical site infection & 0 & 2 & \\
\hline Pneumonia & 0 & 1 & \\
\hline Postoperative resumption of food intake (day, median) & 6 & 8 & 0.082 \\
\hline Postoperative hospital stay (day, median) & 15 & 16 & 0.528 \\
\hline
\end{tabular}

first operation may lead to substantial changes in lymphatic flow from the remnant stomach, making surgical control of RGC with nodal disease difficult (7). The clinicopathological features of RGC have been analyzed in some reports, as summarized in Table V. Our study showed that the number of dissected and metastatic lymph nodes was larger in the Ulcer group than in the Carcinoma group. In the Ulcer group, right cardiac (No.1) and lesser curvature (No.3) lymph nodes were dissected during surgery for RGC. Meanwhile, in the Carcinoma group, these lymph nodes were already dissected during the initial surgery. Therefore, the number of metastatic lymph nodes might not always reflect the severity of disease for the Carcinoma group. Instead, it has been suggested that other factors, such as histological type, lymphatic invasion, and vascular invasion, could be indicators of malignant potential of RGC.

We previously reported four cases with RGC who underwent LPG at our hospital and demonstrated the favorable short-term results (4). Another previous study reported that operation time was longer in LTG than in OTG (7). Meanwhile, blood loss, complications, and postoperative hospital stay were reported to be less in LTG than in OTG (3). In our study, the results were consistent with those of previous reports. There was also no significant difference in the number of lymph node dissections between patients undergoing LTG of OTG. Surgical resection is more difficult in patients undergoing RGC than in patients with primary gastric cancer because of the severity of adhesions. In particular, LTG is more technically difficult than OTG. Although the oncological feasibility remains to be fully established, laparoscopy provides a magnified view of minute structures, such as tiny vessels and nerves (8), which
Table III. Clinicopathological characteristics of remnant gastric cancer according to surgical procedure (OTG group vs. LTG group).

\begin{tabular}{|c|c|c|c|c|}
\hline \multirow[b]{2}{*}{ Factor } & \multicolumn{2}{|c|}{ Surgical procedure } & \multirow[b]{2}{*}{ Total } & \multirow[b]{2}{*}{$p$-Value } \\
\hline & $\begin{array}{l}\text { OTG } \\
(\mathrm{n}=18)\end{array}$ & $\begin{array}{c}\text { LTG } \\
(\mathrm{n}=4)(\mathrm{n}=22)\end{array}$ & & \\
\hline \multicolumn{5}{|l|}{ Gender } \\
\hline Male & $15(83.3)$ & $3(75.0)$ & $18(81.8)$ & 0.69 \\
\hline Female & $3(16.7)$ & $1(25.0)$ & $4(18.2)$ & \\
\hline \multicolumn{5}{|l|}{ Age (mean) } \\
\hline$<65$ & $3(16.7)$ & $0(0)$ & $3(13.6)$ & 0.70 \\
\hline$>65$ & $15(83.3)$ & $4(100)$ & $19(86.4)$ & \\
\hline \multicolumn{5}{|l|}{ Depth of tumor } \\
\hline $\mathrm{T} 1 / 2$ & $11(61.1)$ & $2(50)$ & $13(59.1)$ & 0.68 \\
\hline $\mathrm{T} 3 / 4$ & $7(38.9)$ & $2(50)$ & $9(41.0)$ & \\
\hline \multicolumn{5}{|l|}{$\begin{array}{l}\text { Lymph node } \\
\text { metastasis }\end{array}$} \\
\hline No & $13(72.2)$ & $3(75.0)$ & $16(72.7)$ & 0.91 \\
\hline N1 & $5(27.8)$ & $1(25.0)$ & $6(27.3)$ & \\
\hline \multicolumn{5}{|l|}{$\begin{array}{l}\text { Differentiation of } \\
\text { adenocarcinoma }\end{array}$} \\
\hline Well/moderate & $11(61.1)$ & $2(50)$ & $13(59.1)$ & 0.68 \\
\hline Poorly & $7(38.9)$ & $2(50)$ & $10(45.5)$ & \\
\hline \multicolumn{5}{|c|}{ Lymphatic invasion } \\
\hline Ly $(-)$ & $8(44.4)$ & $2(50)$ & $10(45.5)$ & 0.84 \\
\hline Ly (+) & $10(45.6)$ & $2(50)$ & $12(54.5)$ & \\
\hline \multicolumn{5}{|l|}{ Vascular invasion } \\
\hline V (-) & $13(72.2)$ & $3(75.0)$ & $16(72.7)$ & 0.91 \\
\hline $\mathrm{V}(+)$ & $5(27.8)$ & $1(25.0)$ & $6(27.3)$ & \\
\hline \multicolumn{5}{|l|}{ Pathological stage } \\
\hline I & $10(55.4)$ & $2(50.0)$ & $12(54.5)$ & 0.32 \\
\hline II & $6(33.4)$ & $2(50.0)$ & $8(36.4)$ & \\
\hline III & $2(11.2)$ & $0(0)$ & $2(10)$ & \\
\hline
\end{tabular}

OTG: Open total gastrectomy; LTG: laparoscopic total gastrectomy. 
a

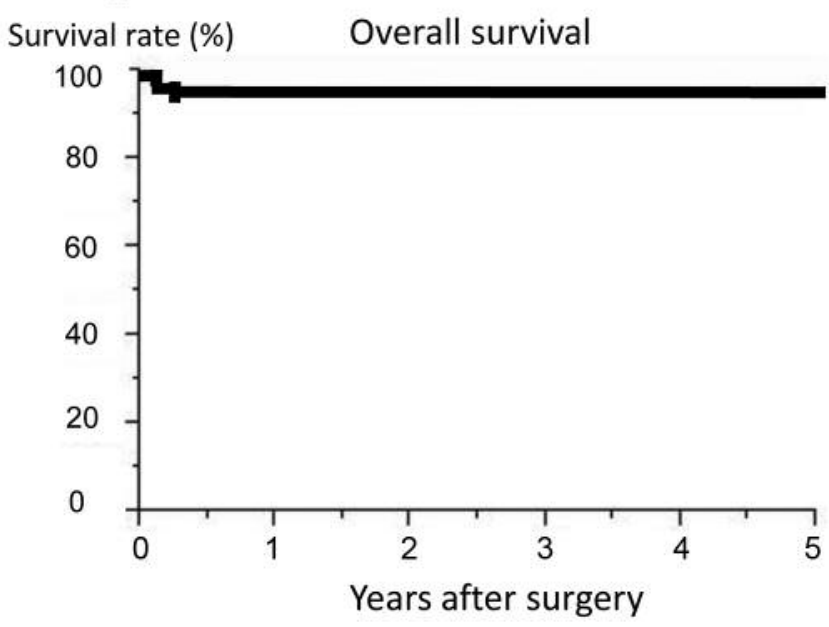

b

Survival rate (\%) Recurrence-free survival

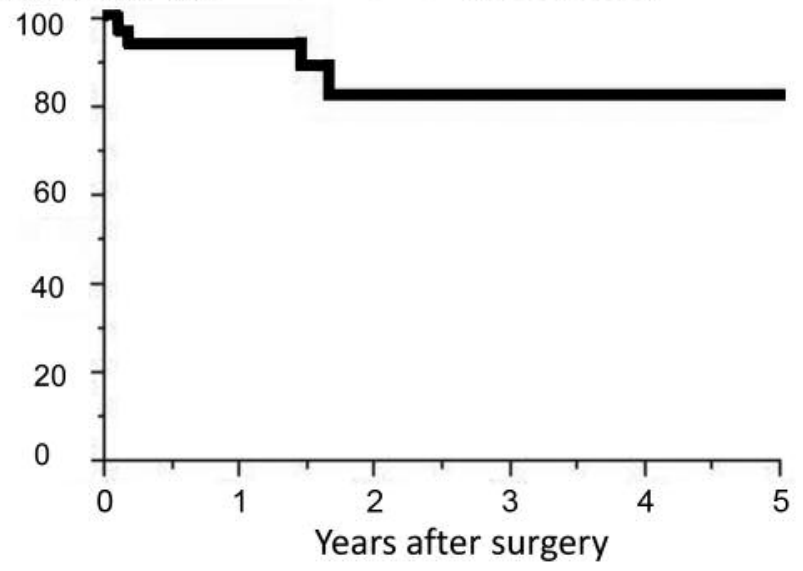

Figure 1. 5-year overall survival (a) and recurrence-free survival (b) in remnant gastric cancer after surgical treatment. 5-Year overall and recurrence-free survival was $94 \%$ and $81 \%$, respectively.

Table IV. Surgical results and pathological findings according to previous disease (OTG group vs. LTG group).

\begin{tabular}{|c|c|c|c|}
\hline & \multicolumn{2}{|c|}{ Surgical procedure } & \multirow[b]{2}{*}{$p$-Value } \\
\hline & OTG group $(n=18)$ & LTG group $(n=4)$ & \\
\hline Number of lymph node dissections (mean) & 11 & 15 & 0.674 \\
\hline Number of lymph node metastasis (mean) & 1.1 & 0.3 & 0.533 \\
\hline Tumor size $(\mathrm{cm}$, mean $)$ & 3.4 & 4.5 & 0.478 \\
\hline Interval between 1 st and 2 nd operations (years, mean) & 18 & 26 & 0.345 \\
\hline Operation time (min, mean) & 293 & 455 & $<0.005$ \\
\hline Blood loss $(\mathrm{ml}$, mean $)$ & 625 & 158 & 0.090 \\
\hline Complication & 5 & 2 & 0.388 \\
\hline Minor leakage & 1 & 0 & \\
\hline Bile leakage & 1 & 0 & \\
\hline Bleeding & 1 & 1 & \\
\hline Surgical site infection & 2 & 0 & \\
\hline Pneumonia & 0 & 1 & \\
\hline Postoperative resumption of food intake (day, median) & 8 & 6 & 0.168 \\
\hline Postoperative hospital stay (day, median) & 16 & 15 & 0.655 \\
\hline
\end{tabular}

OTG: Open total gastrectomy; LTG: laparoscopic total gastrectomy.

Table V. Summary of published series for interval between previous operation.

\begin{tabular}{lccccc}
\hline $\begin{array}{l}\text { Author/Year of } \\
\text { publication }\end{array}$ & $\begin{array}{c}\text { Previous disease } \\
\text { (benign/malignancy) }\end{array}$ & $\begin{array}{c}\text { Interval (Mo) } \\
\text { (median) }\end{array}$ & $\begin{array}{c}\text { Interval (Mo) } \\
\text { (benign/malignancy) }\end{array}$ & $\begin{array}{c}\text { Lymph node metastasis } \\
\text { (negative/positive) }\end{array}$ & $\begin{array}{c}\text { Overall survival } \\
(\%)\end{array}$ \\
\hline Kaneko K et al./1998 & $21 / 22$ & 180 & $288 / 118$ & - & 84 \\
Takano S et al./2006 & $11 / 21$ & - & $360 / 63$ & $20 / 12$ & - \\
Ahn HS et al./2008 & $13 / 45$ & 150 & $384 / 83$ & $25 / 19$ & - \\
Ojima T et al./2010 & $17 / 21$ & 180 & $264 / 108$ & $13 / 14$ & - \\
Komatsu S et al./2012 & $19 / 14$ & 240 & $360 / 144$ & $16 / 6$ & - \\
Current Study & $6 / 16$ & 150 & $420 / 144$ & 94 \\
\hline
\end{tabular}

Mo: Months. 
allows lymphadenectomy to be more precisely performed, potentially leading to less intraoperative blood loss and fewer postoperative complications (9-11). However, further studies are required because the number of cases in our study was too small to draw any conclusion about the significance of LTG for RGC.

We previously reported the short-term surgical results of four cases with RGC who underwent laparoscopic gastrectomy (4). The long-term results of these four cases were additionally reported in the current study. It has been reported that there were no significant differences in terms of long-term results between OTG and LTG (1, 3, 8, 12-14). In our study, 5 of the 22 patients received adjuvant chemotherapy. Eighteen of the 22 cases survived without recurrence, including these 5 cases. The 5 -year overall and recurrence free survival rates were $94 \%$ and $81 \%$, respectively. It has been reported that the prognosis of RGC is unfavorable compared to that of primary gastric cancer, which may result from the more advanced stage of disease at the time of diagnosis (12-14). Surgery for RGC is an uncommonly performed procedure. Although our current results were based on a retrospective analysis of a small number of patients, these findings suggest that the surgical outcomes for RGC might be as poor as has been reported until now. Therefore, since prospective trials in this field are currently difficult or impractical, additional retrospective studies can provide useful information regarding the biological features of and appropriate treatment for RGC.

\section{Conclusion}

The results from our study demonstrated that surgical treatment for RGC was feasible and effective in terms of short- and long-term outcomes. Since the number of lymph node dissections and lymph node metastases was quite different according to disease history, the status of lymph node metastasis after surgery for RGC should be cautiously interpreted. Both LTG and OTG can be treatment options for RGC.

\section{References}

1 Komatsu S, Ichikawa D, Okamoto K, Ikoma D, Tsujiura M, Nishimura Y, Murayama Y, Shiozaki A, Ikoma H, Kuriu Y, Nakanishi M, Fujiwara H, Ochiai T, Kokuba Y and Otsuji E: Progression of remnant gastric cancer is associated with duration of follow-up following distal gastrectomy. World J Gastroenterol 18: 2832-2836, 2012. PMID: 22719193, DOI: 10.3748/ wjg.v18.i22.2832

2 Nagai E, Nakata K, Ohuchida K, Miyasaka Y, Shimizu S and Tanaka M: Laparoscopic total gastrectomy for remnant gastric cancer: feasibility study. Surg Endosc 28: 289-296, 2014. PMID: 24013469, DOI: 10.1007/s00464-013-3186-y
3 Son SY, Lee CM, Jung DH, Lee JH, Ahn SH, Park DJ and Kim HH: Laparoscopic completion total gastrectomy for remnant gastric cancer: a single-institution experience. Gastric Cancer 18: 177-182, 2015. PMID: 24477417, DOI: 10.1007/s10120-014-0339-1

4 Korehisa S, Ohgaki K, Yukaya T, Zaitu Y, Tsuda Y, Kasagi Y, Ando K, Nakashima Y, Imamura Y, Saeki H, Oki E and Maehara Y: Laparoscopic total gastrectomy for RGC: Four case reports. Anticancer Res 35: 5023-5026, 2015. PMID: 26254402

5 Biondi A and Hyung WJ: Seventh Edition of TNM Classification for Gastric Cancer. J Clin Oncol 29: 4338-4339, 2011. PMID: 22010017, DOI: 10.1200/JCO.2011.36.9900

6 Dindo D, Demartines $\mathrm{N}$ and Clavien PA: Classification of surgical complications. Ann Surg 240: 205-213, 2004. PMID: 15273542

7 Ohashi M, Katai H, Fukagawa T, Gotoda T, Sano T and Sasako M: Cancer of the gastric stump following distal gastrectomy for cancer Br J Surg 94: 92-95, 2007. PMID: 17054314, DOI: $10.1002 /$ bjs. 5538

8 Kanaya S, Haruta S, Kawamura Y, Yoshimura F, Inaba K, Hiramatsu Y, Ishida Y, Taniguchi K, Isogaki J and Uyama I: Video: laparoscopy distinctive technique for suprapancreatic lymph node dissection: Medial approach for laparoscopic gastric cancer surgery. Surg Endosc 25: 3928-3929, 2011. PMID: 21660629, DOI: 10.1007/s00464-011-1792-0

9 Tsunoda S, Okabe H, Tanaka E, Hisamori S, Harigai M, Murakami K and Sakai Y: Laparoscopic gastrectomy for remnant gastric cancer: a comprehensive review and case series. Gastric Cancer 19: 287-292, 2016. PMID: 25503677, DOI: 10.1007/s 10120-014-0451-2

10 Kimura Y, Oki E, Ando K, Saeki H, Kusumoto T and Maehara Y: Incidence of venous thromboembolism following laparoscopic surgery for gastrointestinal cancer: A single-center, prospective cohort study. World J Surg 40: 309-314, 2016. PMID: 26316113, DOI: $10.1007 / \mathrm{s} 00268-015-3234-y$

11 Kwon IG, Cho I, Guner A, Choi YY, Shin HB, Kim HI, An JY, Cheong JH, Noh SH and Hyung WJ: Minimally invasive surgery for remnant gastric cancer: A comparison with open surgery. Surgical Endosc 28: 2452-2458, 2014. PMID: 24622766, DOI: 10.1007/s00464-014-3496-8

12 Takeno S, Hashimoto T, Maki K, Shibata R, Shiwaku H, Yamana I, Yamashita R and Yamashita Y: Gastric cancer arising from the remnant stomach after distal gastrectomy: A review. World $\mathrm{J}$ Gastroenterol 20: 13734-13740, 2014. PMID: 25320511, DOI: 10.3748/wjg.v20.i38.13734

13 Ahn HS, Kim JW, Yoo MW, Park DJ, Lee HJ, Lee KU and Yang HK: Clinicopathological features and surgical outcomes of patients with remnant gastric cancer after a distal gastrectomy. Ann Surg Oncol 15: 1632-1639, 2008. PMID: 18379851, DOI: 10.1245/s10434-008-9871-8

14 Ojima T, Iwahashi M, Nakamori M, Nakamura M, Naka T, Katsuda M, Iida T, Tsuji T, Hayata K, Takifuji K and Yamaue H: Clinicopathological characteristics of remnant gastric cancer after a distal gastrectomy. J Gastrointest Surg 14: 277-281, 2010. PMID: 19911236, DOI: 10.1007/s11605-009-1090-5

Received November 25, 2018 Revised January 20, 2019 Accepted January 29, 2019 